\title{
OPEN Field evidence for microplastic interactions in marine benthic invertebrates
}

\author{
Stefania Vecchi ${ }^{1 \bowtie}$, Jessica Bianchi ${ }^{2}$, Massimiliano Scalici $^{1 凶}$, Fabrizio Fabroni $^{3} \&$ \\ Paolo Tomassetti ${ }^{4}$
}

Microplastics represent an important issue of concern for marine ecosystems worldwide, and closed seas, such as the Mediterranean, are among the most affected by this increasing threat. These pollutants accumulate in large quantities in benthic environments causing detrimental effects on diverse biocenoses. The main focus of this study is on the 'polychaetes-microplastics' interactions, particularly on two species of benthic polychaetes with different ecology and feeding strategies: the sessile and filter feeder Sabella spallanzanii (Gmelin, 1791) and the vagile carnivorous Hermodice carunculata (Pallas, 1766). Since not standardized protocols are proposed in literature to date, we compared efficiencies of diverse common procedures suitable for digesting organic matter of polychaetes. After the definition of an efficient digestion protocol for microplastics extraction for both polychaetes, our results showed high microplastics ingestion in both species. Microplastics were found in $42 \%$ of individuals of S. spallanzanii, with a mean of $1( \pm 1.62)$ microplastics per individual, in almost all individuals of $H$. carunculata $(93 \%)$, with a mean of $3.35( \pm 2.60)$. These significant differences emerged between $S$. spallanzanii and $H$. carunculata, is probably due to the diverse feeding strategies. The susceptibility to this pollutant makes these species good bioindicators of the impact of microplastics on biota.

Since 1950s, plastic was produced and utilized more and more frequently ${ }^{1}$ and, to date, this material is the biggest polluting anthropogenic debris in marine environment ${ }^{2}$. On the sea's surface float 5 trillion of plastic particles, weighing more than 260,000 tons $^{3}$. Due to its physical-chemical properties and environmental characteristics, plastic degrades very slowly and it can persist in marine environment for thousands of years ${ }^{4}$.

Hydrodynamic and meteorological factors (e. g. sea current velocity, density of water mass, temperature and wind), anthropic factors (e. g. urban and industrial activities) and physical-chemical properties of plastics (shape, density, size, chemical composition) can influence their transport dynamics and accumulation in marine environment ${ }^{5}$.

The plastic accumulation within the Mediterranean Sea basin is a particularly intense process, so that our sea is considered one of the most plastic-polluted areas worldwide, and exactly the sixth great accumulation zone of marine litter ${ }^{6}$. The main factors driving this pollution are the enclosed structure of basin, the scarce outflow of surface waters, the high population density along coastlines, and the intensive fishing, tourism, shipping and industrial activities ${ }^{7}$.

Plastics are on the ocean's surface, along the water column and in seafloor worldwide ${ }^{8}$, and all over the world benthic environments are considered sinks for microplastics as well. Benthos accumulate plastics in considerable quantities, putting at risk the health of benthic communities ${ }^{9}$. Plastic affecting marine environments can be categorized according to different size classes: mega ( $>1 \mathrm{~m}$ diameter), macro (between $2.5 \mathrm{~cm}$ and $1 \mathrm{~m}$ ), meso (between $5 \mathrm{~mm}$ and $2.5 \mathrm{~cm}$ ), micro (between $1 \mu \mathrm{m}$ and $5 \mathrm{~mm}$ ) and nano $(<0.1 \mu \mathrm{m})^{10}$.

Microplastics (MPs), due to their small size, are a threat to the aquatic biota because MPs can be ingested by a wide range of marine organisms. Indeed, several studies demonstrated that many marine species, both vertebrates and invertebrates, to different trophic levels and with various feeding strategies ingest microplastics, such as marine birds, mammals, reptiles, fish and diverse invertebrates ${ }^{11-16}$. Ingestion can take place directly, accidentally assimilating throughout filter-feeding or deposit-feeding or confusing for food, indirectly, by ingesting prey of

\footnotetext{
${ }^{1}$ Department of Sciences, University of Roma Tre, Viale G. Marconi 446, 00146 Rome, Italy. ${ }^{2}$ Department of Ecology and Biology, University of Tuscia, Via S. Camillo de Lellis 44, 01100 Viterbo, VT, Italy. ${ }^{3}$ ARPACAL, Regional Agency for Environmental Protection, Zona Industriale 1, 89900 Vibo Valentia, VV, Italy. ${ }^{4}$ talian National Institute for Environmental Protection and Research, ISPRA, Via di Castel Romano 100, 00144 Rome, RM, Italy. ${ }^{\square}$ email: stefania.vecchi92@gmail.com; massimiliano.scalici@uniroma3.it
} 
lower trophic levels which contain microplastics ${ }^{17}$. This event can bring to different biological and ecological effect, as internal physical and chemical damage, trophic transfer and biomagnification, absorption to microplastics surfaces of other contaminants such as heavy metal, antibiotics, polycyclic aromatic hydrocarbons and polychlorinated bisphenols, transport of pathogens and alien species that colonize microplastic surface ${ }^{18}$.

Several studies have highlighted differences in microplastics ingestion between feeding models, in fact, some studies show a highest microplastic concentration in suspension feeders ${ }^{13,19}$ while others show a greater microplastic concentration in deposit-feeders or predator as compared to other feeding strategies ${ }^{12,20}$.

Coastal marine invertebrates are potentially affected by coastal pollutants, such as plastic debris, and their interactions could happen at various ecological levels. Among marine invertebrates, polychaete are good indicators and they are useful for detecting environmental alterations due to their response to cumulative factors of natural or anthropogenic origin. Polychaetes are widely distributed, and, in the benthic domain, they constitute $35-70 \%$ of macroinvertebrate populations ${ }^{21}$. Polychaetes present all the feeding schemes that can be found among benthic organisms, omnivores, herbivores, carnivores, filter feeders, surface deposit feeder and burrowers, so they can uptake MPs under several trophic ways.

Several studies have been conducted on the MPs ingestion by polychaetes in various parts of the world ${ }^{20,25,44,45}$, while in the Mediterranean Sea few studies have been conducted on this. These latest studies have examined the ingestion of microfibres in annelid species of Saccocirrus (Bobretzky, 1872) ${ }^{22}$, MPs in seaworms (Muller, 1776) ${ }^{23}$ and MPs occurrence in six benthic invertebrate species, including the polychaete Hediste diversicolor ${ }^{24}$.

There are different methods and protocols to detect MPs within of the polychaetes, some of them involve the digestion of the whole organism ${ }^{12,20,23-25}$. In fact, to isolate MPs present in marine organisms can be challenging because the plastic may be hidden by biological materials, therefore most procedures involve the digestion of organic matter ${ }^{26}$.

Considering the importance of this environmental issue, the first aim of the present study is to assess the interaction between MPs and benthic organisms naturally exposed through the study of ingestion in two species of benthic polychaetes with different ecological features.

In this study we have preliminarily selected the most suitable environmental indicators of this type of pressure among the polychaete species present along the Italian coasts. We then analysed all the methods of study and analysis of MPs in marine organisms to choose the one that, better than others, suited the purposes of the research. The weighted analysis of the ecological characteristics and study of the polychaete species present along the Italian coasts led to the choice of the Mediterranean fanworm Sabella spallanzanii (Gmelin 1791) and the bearded fireworm Hermodice carunculata (Pallas, 1766).

For this purpose, considering the unavailability of well-established methods, the other study aim is also define a protocol to extraction of MPs by the organisms to make the appropriate assessments. The results of the present contribute to give detailed information about MP contamination level of polychaetes and offer a well-established MP detection method in marine invertebrates.

\section{Results}

Different protocols comparison and Method adjustment. The digestion efficiency obtained with $\mathrm{KOH}$ at $60^{\circ} \mathrm{C}$ for $24 \mathrm{~h}$ (Protocol 1) was $90 \%$, for the protocol $2\left(\mathrm{H}_{2} \mathrm{O}_{2}\right.$ at $50{ }^{\circ} \mathrm{C}$ for $12 \mathrm{~h}$ ) was $96 \%$ and finally, for the treatment with $\mathrm{KOH}$ at $10 \%$ at room temperature for 2-3 weeks (protocol 3) was $96 \%$.

Protocols 2 and 3 showed an acceptable digestion efficiency $(>95 \%)$. The Protocol 1, with a digestion efficiency $<95 \%$, was not satisfactory and showed a wide variability compared to the other two protocols as the maximum and minimum values differ considerably from the central value (Fig. 1).

This variability was confirmed by the Levene test (modified robust Brown-Forsy the Levene-type) based on the absolute deviations from the median. This test showed the non-homogeneity of the variances $(p<0.05)$ (Table 1$)$. Hence protocol 1 was discarded due to both low digestion efficiency and high variance.

Wilcoxon test was performed on the digestion efficiencies of protocols 2 and 3 . The test showed no significant difference between the two protocols $(p>0.05)$ (Table 1$)$. Therefore, for these two protocols we also considered the differences in membrane clogging.

The Wilcoxon test did not reveal any significant differences between the two tested protocols $(p>0.05)$ for membrane clogging (Table 1).

As both tests did not show significant differences between the two protocols, we conclude that they are equally efficient.

Qualitative considerations were made to choose the protocol to be applied to the polychaete samples. In the samples treated with $15 \% \mathrm{H}_{2} \mathrm{O}_{2}$ a foam layer was observed not only during the digestion step, but also on the filters during filtration step. For this reason, subsequent optical examination of MPs proved particularly complicated. These problems were not found in the samples treated with $10 \% \mathrm{KOH}$.

For these reasons, protocol 3 was chosen for the analysis of real samples.

For $H$. carunculata additional evidences required an adjustment of the analytical approach. In fact, the numerous chaetes present in this species have not been completely digested by potassium hydroxide.

Since the chaetes are calcareous, a $\mathrm{HNO}_{3}$ at $5 \%$ e di $\mathrm{H}_{2} \mathrm{O}_{2}$ at $15 \%$ mixture was chosen to dissolve them. The results showed an almost complete digestion of the chaetes (Fig. 2).

Microplastics in field collected samples. Microplastics have been found in both species. Fibers were found in great quantity but were excluded from the analysis. Only fragments and films were considered.

In total, 52 items were observed in $S$. spallanzanii samples, with a mean $( \pm$ SE $)$ of $1( \pm 1.62)$ microplastics per individual ( $0.1 \pm 0.2$ particles/gram of tissue); 22 out of 52 individuals in total ingested MPs $(\mathrm{FO}=42 \%)$. 


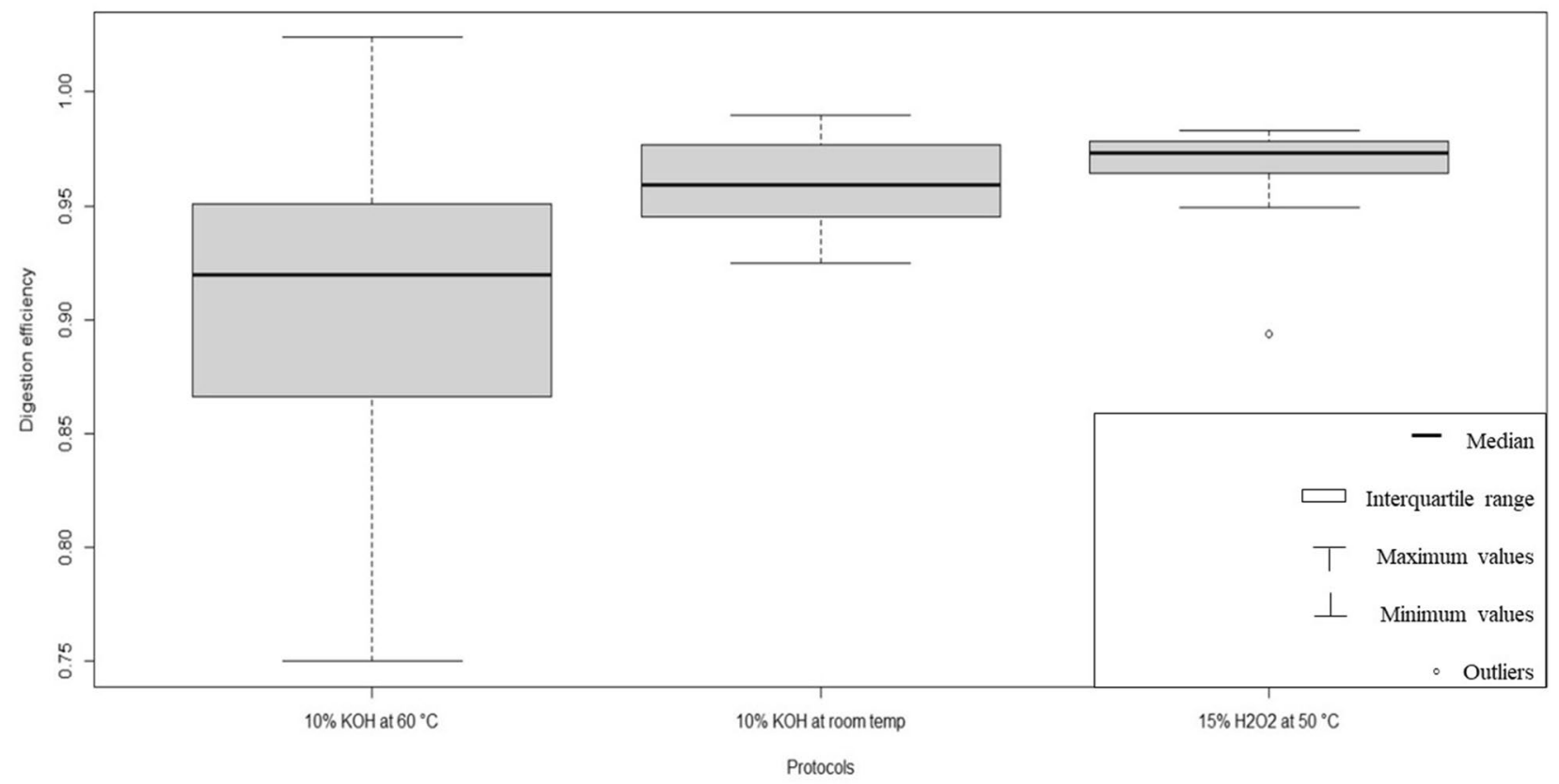

Figure 1. Protocol selection in Sabella spallanzanii. Box and whiskers plot of three digestion protocols ( $10 \%$ $\mathrm{KOH}$ at $60{ }^{\circ} \mathrm{C}, 10 \% \mathrm{KOH}$ at room temp and $15 \% \mathrm{H}_{2} \mathrm{O}_{2}$ at $50{ }^{\circ} \mathrm{C}$, respectively from left to right protocols 1,2 and 3). Protocols with a digestion efficiency greater than $95 \%$ are accepted. Protocols with more robust data are those with a narrow interquartile range. The figure is obtained by the software R (ver. $4.514,597.0$, https:// cloud.r-project.org).

\begin{tabular}{|c|c|c|}
\hline Protocols' comparisons & Statistical analysis & Test and $p$ value \\
\hline a) Digestion efficiency comparation (protocols 1,2 and 3) & $\begin{array}{l}\text { Modified robust Brown-Forsythe Levene-type test based on the absolute deviations from } \\
\text { the median }\end{array}$ & $\mathrm{B}-\mathrm{F}=6.5043, p=0.004947$ \\
\hline b) Digestion efficiency comparation (protocols 2 and 3 ) & Wilcoxon rank sum test & $\mathrm{W}=64, p=0.315$ \\
\hline c) Membrane clogging comparation (protocol 2and 3) & Wilcoxon rank sum test & $\mathrm{W}=44, p=0.6842$ \\
\hline
\end{tabular}

Table 1. Statistical analysis with Leven test (B-F) and Wilcoxon rank sum test (W) and p-value of all protocols comparations in Sabella spallanzanii samples. A $p<0.05$ in the B-F test (a) indicate a non-homogeneity of the variances. A $p>0.05$ in the $\mathrm{W}$ test $(\mathrm{b}-\mathrm{c})$ indicate any significant difference between protocols. The statistical analysis are obtained by the software R (ver. 4.5 14,597.0, https://cloud.r-project.org).

Instead, 184 items were observed in $H$. carunculata samples, with a mean $( \pm$ se $)$ of $3.35( \pm 2.60)$ microplastics per individual $(0.8 \pm 1.0$ particles/gram of tissue). Most samples have ingested MPs, 51 out of 55 individuals $(\mathrm{FO}=91 \%)$.

MPs ingestion significantly differed in the abundance and frequency of occurrence, in particular more MPs have been found in H. carunculata than in S. spallanzanii (Table 2).

In S. spallanzanii the fragments were found in large quantities (81\%) followed by films (19\%) (Fig. 3). Various colors were observed: transparent items (38\%), red/pink (31\%), blue (19\%), green (6\%), black (4\%) and white (2\%) (Fig. 3). According to size classes, 22 MPs were found in the class 2 (42\%), 15 in the class 1 and in the class 3 (29\%) (Fig. 3).

In H. carunculata the fragments were the dominant MPs shape (99\%), only one film was found (1\%) (Fig. 3). Three colors were observed: red/pink items (90\%), blue (7\%), transparent (3\%) (Fig. 3). In all H. carunculata samples the items of the red/pink category are pink. As for the size classes, 148 MPs were found in the class 1 (81\%), 30 in the class $2(16 \%)$ and 6 in the class $3(3 \%)$ (Fig. 3 ).

FT-IR identification confirmed that all isolated particles larger than $330 \mu \mathrm{m}$ were plastic polymers $(\mathrm{x}=52)$. Among the analyzed particles in S. spallanzanii $64 \%$ were made of polyethylene (PE), $15 \%$ of polystyrene (PS), $9 \%$ of polypropylene (PP) and 6\% of polytetrafluoroethylene (PTFE) and a mix of polyethylene and polypropylene (mix PE-PP) (Fig. 3). In H. caunculata 84\% were made of PE, 11\% PS and 5\% NY (Fig. 4).

\section{Discussion}

Techniques used to identify MPs in fish and invertebrates have been adapted from previous studies on large vertebrates (e.g., marine mammals or seabirds ${ }^{26}$. As research on this issue advances, it is essential to implement knowledge with increasingly relevant methods. Because of the difficulties of isolation and identification 


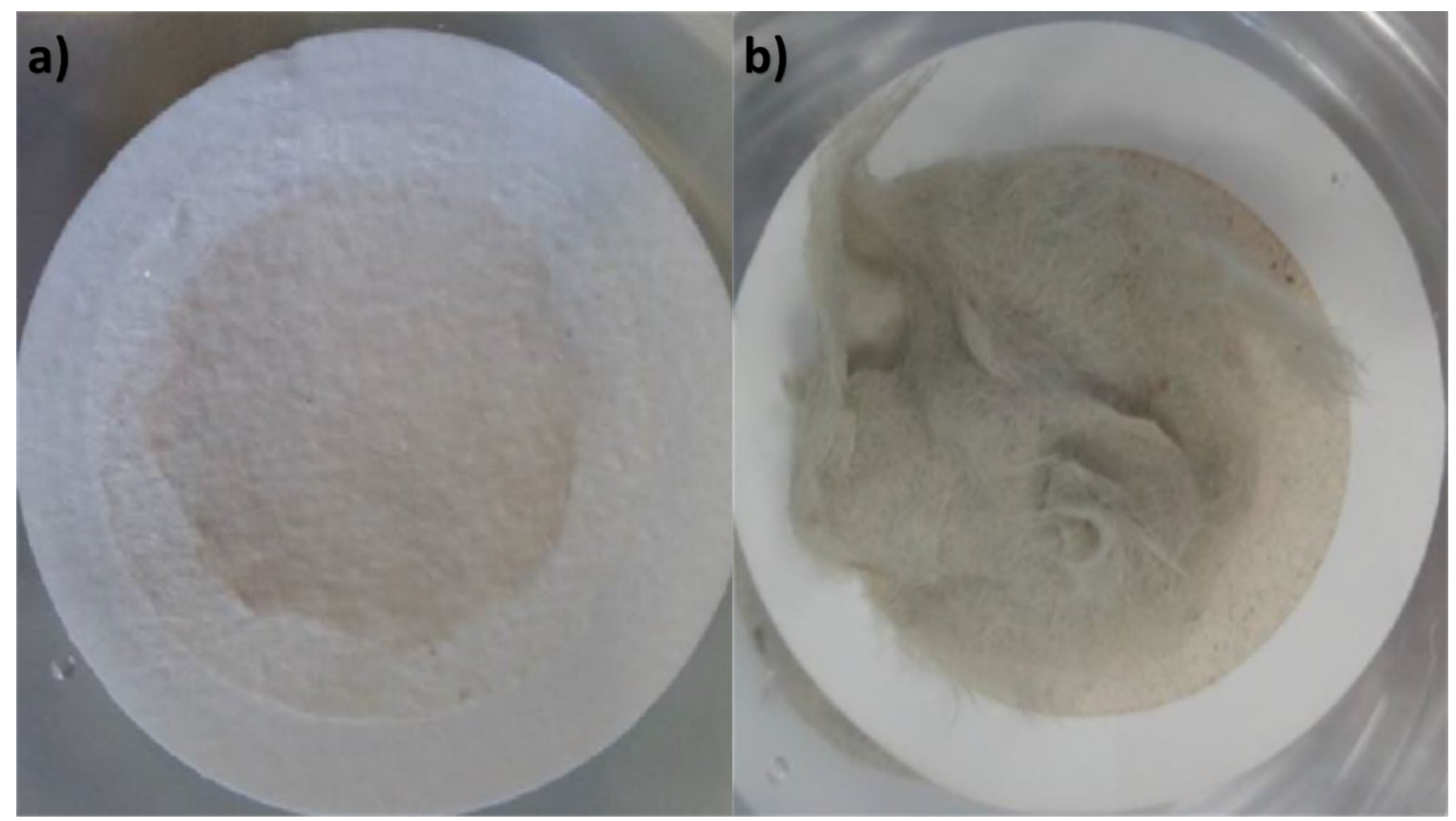

Figure 2. Filter before (a) and after (b) treatment with $\mathrm{HNO}_{3}$ and $\mathrm{H}_{2} \mathrm{O}_{2}$ mixture to dissolve the chaetes of Hermodice carunculata.

\begin{tabular}{|c|c|c|c|c|c|c|c|c|c|c|}
\hline \multirow[b]{2}{*}{ Species } & \multicolumn{5}{|c|}{ Frequency of occurrence } & \multicolumn{5}{|c|}{ Abundance } \\
\hline & Estimate & S.E & $\mathrm{z}$ value & $\operatorname{Pr}(>|\mathrm{z}|)$ & Signif. codes & Estimate & S.E & $z$ value & $\operatorname{Pr}(>|z|)$ & Signif. codes \\
\hline Intercept & 2.3026 & 0.4690 & 4.909 & $9.15 \mathrm{e}-07$ & $* * *$ & 1.30291 & 0.09027 & 14.434 & $<2 \mathrm{e}-16$ & $* * *$ \\
\hline Sabella spallanzanii & -2.6127 & 0.5466 & -4.780 & $1.75 \mathrm{e}-06$ & $* * *$ & -0.44271 & 0.18315 & -2.417 & 0.0156 & * \\
\hline
\end{tabular}

Table 2. Estimates, standard error (S.E.), z-value and $p$-values with significant code $\left(^{*}\right)$ of Generalized Linear Models (GLM) analysis to assess differences in microplastics ingested by Sabella spallanzanii and Hermodice carunculata. ${ }^{1}$ Intercept $=$ Hermodice carunculata. Significance codes: ${ }^{\star} p<0.05 ;{ }^{* \star} p<0.01 ;{ }^{* \star} p<0.001$. All the frequency of occurrence and abundance value are obtained by the software R (ver. 4.5 14,597.0, https://cloud.rproject.org).

microplastics and the different physiology of taxonomic groups under consideration, a degree of flexibility and innovation is clearly required.

Since there are few studies that use digestion methods applied to polychaetes, in this research are used protocols (tested to study the ingestion of microplastics in the fishes) to digest organic matter of the polychaetes.

Among the digestion methods utilized we chose the most common in literature, that are a $10 \%$ potassium hydroxide $(\mathrm{KOH})$ solution ${ }^{27,28}$ and hydrogen peroxide $\left(\mathrm{H}_{2} \mathrm{O}_{2}\right)^{29,30}$ and nitric acid $\left(\mathrm{HNO}_{3}\right)^{12,31,32}$, but the latter, it is advisable to use it at low concentrations, because it could corrode microplastics we are looking for. The choice of chemical treatment depends on how well it digests the organic matter and its corrosiveness towards plastic polymers.

Therefore, we excluded protocols with high concentration such as $69 \%$ of $\mathrm{HNO}_{3}$, because at this concentration it is certainly corrosive even to microplastics inside the organism ${ }^{32}$, or protocols that use $\mathrm{NaOH}$ because it is a less effective digestive agent than others and, moreover, it degrades some plastic polymers ${ }^{33,34}$.

The results, obtained from the comparison among the three protocols, led to the final choice, that is the Foekema protocol ${ }^{27}(10 \% \mathrm{KOH}$ solution at room temperature for 2-3 weeks) as defined treatment. Potassium hydroxide is a widely used reagent in the alkaline digestion of the organic matter for the extraction of microplastics from biota, in polychaetes, in other invertebrates and in gastrointestinal tract of the vertebrates ${ }^{27,28,34-36}$.

The Foekema protocol applied to S. spallanzanii is used for H. carunculata samples, but these have a lot of chaetes that during the procedure are not completely digested. So, it was necessary to perform a second digestion for the only chaetes of this species. For this phase we have applied a new protocol tested in an article that highlighted how different chemical reason implicated in the digestion have a different effect depending on matter to digest $^{32}$. In particular, oxidative reaction, with reagent as hydrogen peroxide and nitric acid at low concentrations, are recommended for hard substrate such as chitinous exoskeletons and carbonate shells ${ }^{32}$. Since H. carunculata 

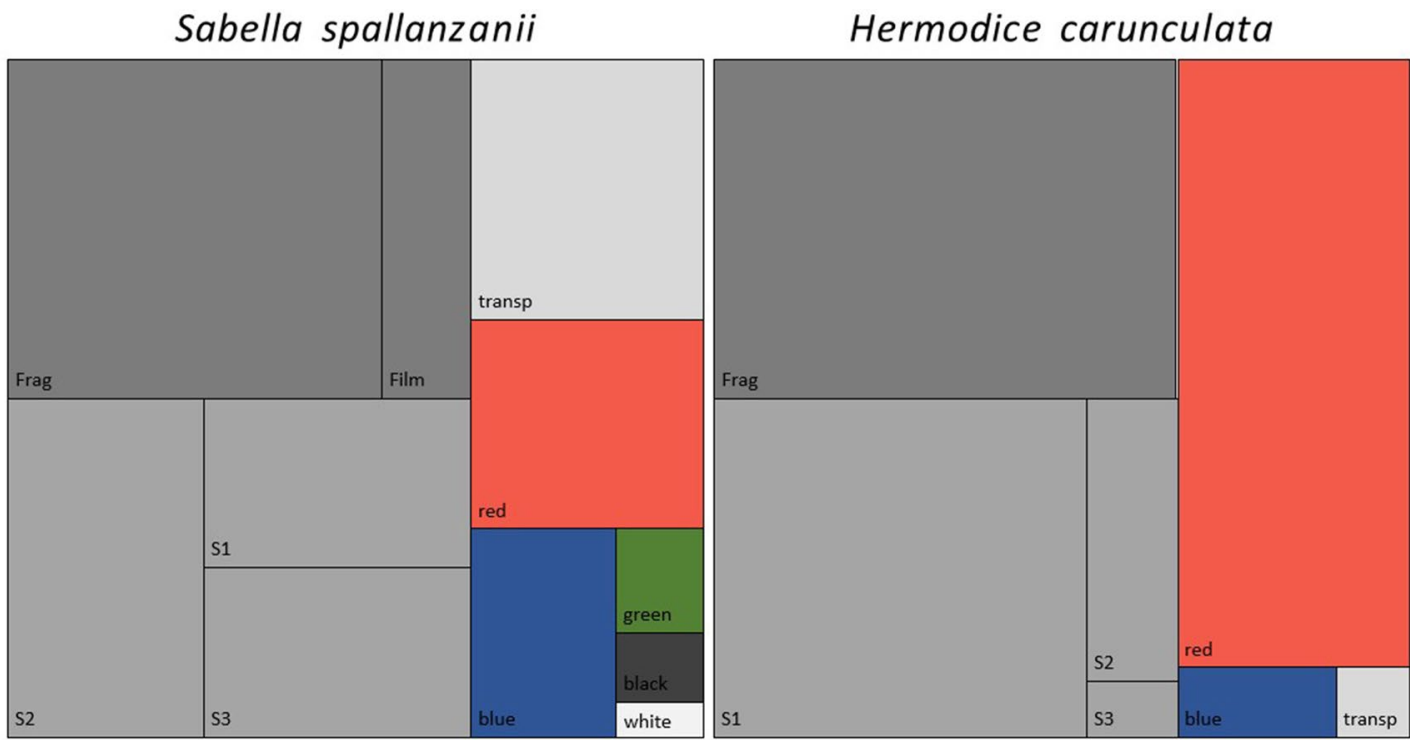

Figure 3. Physical characterization of ingested microplastics by Sabella spallanzanii and Hermodice carunculata. A treemap chart (Excel) with shape categories (Frag: fragments; Film: films), size classes (S1: size class 1, $90 \mu \mathrm{m}-330$; S2: size class 2, $330 \mu \mathrm{m}-1 \mathrm{~mm}$; S3: size class 3, 1-5 mm) and colour (transp: transparent; red: red; blue; green: green; black: black; white: white). The image is obtained by the software Excel (ver. 2014, https://www.microsoft.com/it-it/microsoft-365/excel) and the software PowerPoint (ver. 2014, https://www. microsoft.com/it-it/microsoft-365/powerpoint).

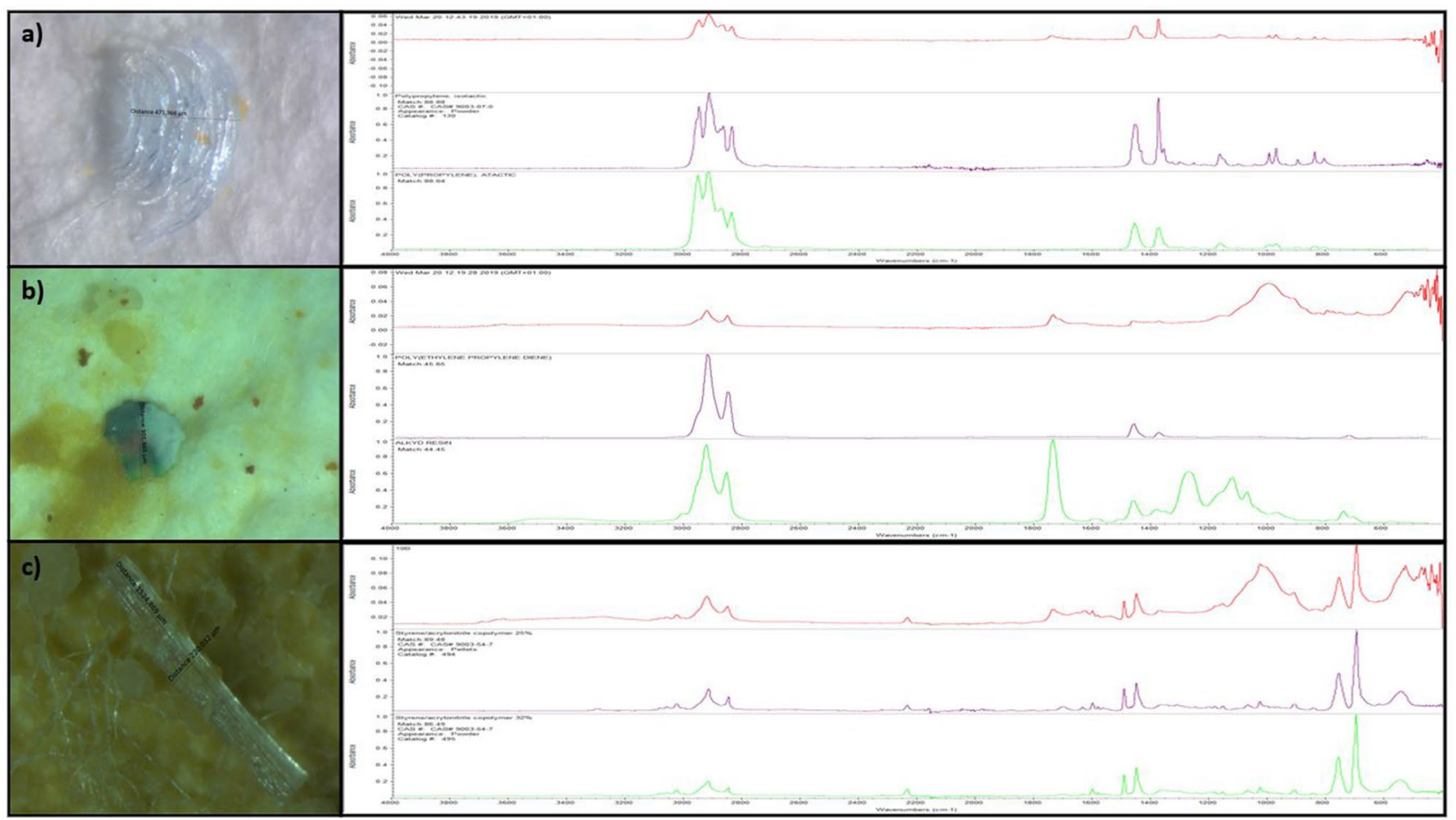

Figure 4. Chemical characterization of ingested microplastics by Sabella spallanzanii and Hermodice carunculata. Picture and infrared spectra of three items are reported. (a) polypropylene (PP) fragment found in Sabella spallanzanii. (b) mix polyethylene-polypropylene (mix PE-PP) fragment found in Sabella spallanzanii. (c) polystyrene (PS) fragment found in Sabella spallanzanii. The pictures are obtained by the software of image for microscope ZEN 2011 SP1 blue edition (6.1.7601) and the FT-IR spectra are obtained by the software OMNIC 9.8.286 (Thermo Fisher Scientific Inc.). 


\begin{tabular}{|c|c|c|c|}
\hline Location & Species & Mps/individual or gram & Authors \\
\hline Adriatic Sea & Hediste diversicolor & Only $1 \mathrm{mps}$ in 100 individuals & (a) Piarulli et al. (2020) \\
\hline Tunisian coast of Mediterranean Sea & Hediste diversicolor & From 0.5 to $3.7 \mathrm{mps} / \mathrm{gram}$ & (b) Missawi et al. (2020) \\
\hline \multirow{3}{*}{ North Sea and Barents Sea } & Galathowenia oculata & \multirow{3}{*}{$0.78 \pm 0.59 \mathrm{mps} /$ individual } & \multirow{3}{*}{ (c) Knutsen et al. (2020) } \\
\hline & Galathowenia fragili & & \\
\hline & Owenia borealis & & \\
\hline \multirow{2}{*}{ Oslofjord } & Hediste diversicolor & \multirow{2}{*}{$1-2 \mathrm{mps} /$ individual } & \multirow{2}{*}{ (d) Bour et al. (2018) } \\
\hline & Sabella pavonina & & \\
\hline $\begin{array}{l}\text { French, Belgian and Dutch coasts in the } \\
\text { North Sea }\end{array}$ & Arenicola marina & $1.2 \pm 2.8 \mathrm{mps} /$ gram & (e) Van Cauwenberghe et al. (2015) \\
\hline
\end{tabular}

Table 3. Some studies that investigate the presence of microplastics (Mps) in polychaetes in different parts of the world.

chaetes are calcareous the protocol developed in this article is applied. As expected, the mixture $\left(5 \% \mathrm{HNO}_{3}+15 \%\right.$ $\mathrm{H}_{2} \mathrm{O}_{2}$ ) digested the chaetes efficiently.

In addition to the experimental approach, this work provides data on the presence and characteristics (shape, size, color, polymer) of microplastics in benthic polychaetes with different feeding models.

Studies on microplastics ingestion in polychaetes have already been conducted in different parts of the world $12,13,20,22,25,37-45$.

Instead, in Mediterranean Sea there are few studies concerning that subject ${ }^{23,24}$. This work is the first to investigate the presence of microplastics in the polychaetes S. spallanzanii and H. carunculata from their natural habitat, in the Mediterranean Sea.

The current study shows the highest concentrations and frequency of occurrence in $H$. carunculata compared to S. spallanzanii. Furthermore, in both polychaetes there were fragment-shaped microplastic particles, made of polyethylene and of small size $(<1 \mathrm{~mm})$ in greater quantity. On the other hand, a difference emerged in the type of color of microplastics founded in the two species (Fig. 3).

This study showed an interaction between microplastics and polychaetes. At the beginning of the study, both species were selected for their biology and ecology and especially for their feeding strategy, as well as for their easy findability. Our results demonstrated that these polychaetes are subjected to this anthropic impact. In particular, concerning the feeding strategy, the data showed highest values in S. spallanzanii compared to H. carunculata, both in terms of abundance and frequency of occurrence.

These two species have a different food strategy: the fanworm is a filter organism, while the green fireworm is a predatory carnivore and deposit-feeders. Feeding behavior and strategy greatly influence the ingestion rate of plastic particles. The results of some studies, although contrasting with each other, show clearly how the quantities of ingested microplastics vary according to the food models ${ }^{13,19,20,39}$. Due to this discrepancy among the results, further studies on microplastics ingestion should be investigated, possibly in field conditions.

From the results obtained in the current study we can assume that filter feeders are less exposed to microplastics than deposit-feeders or carnivorous. In particular, filter-feeders could be more selective towards food particles compared to other organisms, but another explanation could be a different concentration of microplastics between the two sampling areas or a greater availably of microplastics on the sediment surface compared to the water column. The fact that more microplastics are ingested to predator $H$. carunculata could also means that these particles are more easily transferred between species, along feeding web (biomagnification), although a deliberate ingestion of microplastics, confusing for a food particle, cannot be excluded.

Comparing our data with data obtained in a study conducted on the polychaete Hediste diversicolor, sampled in the Adriatic Sea, differences emerged, that is only one microplastic was detected of a total of 100 individuals ${ }^{24}$ (Table 3a). In another study conducted in Mediterranean Sea, along the Tunisian coast, the abundance of microplastics varied (from 0.5 particles/gram to 3.7 particles/gram of tissue) depending on the sampled site and our data is closer to those sites where the concentration of microplastics was lower ${ }^{23}$ (Table $3 \mathrm{~b}$ ).

The results in our samples are similar to these of other polychaetes species outside the Mediterranean. Levels of microplastics have been reported in some polychaetes as Galathowenia oculata (Zachs, 1923), Galathowenia fragili (Nilsen \& Holthe, 1985) and Owenia borealis (Koh, Bhaud \& Jirkov, 2003) sampled in North Sea and Barents Sea, with an overall abundance of $0.78 \pm 0.59$ particles/individuals, although microplastics concentrations are higher in the tube than in the tissue ${ }^{25}$ (Table 3c). In another studies, 1-2 particles/individuals were estimated in Hediste diversicolor and Sabella pavonina (Savigny, 1822), from the inner Oslofjord in Norway ${ }^{20}$ (Table 3d), whereas in the individuals of Arenicola marina (Linnaeus, 1758) collected along the French, Belgian and Dutch coasts in the North Sea, has been founded an average of $1.2 \pm 2.8$ microplastics/gram of tissue ${ }^{12}$ (Table 3e). Instead, in the fecal contents of polychaetes collected along the coasts in South Korea, has been reported a mean of $0.71 \pm 1$ microplastics / gram of tissue ${ }^{45}$. It should be considered that some of the studies mentioned above also evaluated fibers and therefore our results could differ.

However, different extraction methods are utilized to study microplastics presence and characterization in the marine organisms, and this not always allow a correct comparison with species of other studies. For this reason, standardized extraction methods are particularly important.

In this study we have chosen to exclude fibers from the analysis to avoid the overestimation of data, given the large quantity of fibers found. Despite our attention during all the laboratory processes, the possibility of 
environmental contamination is not erased. Since fibers are ubiquitous ${ }^{46}$, it is not possible to exclude environmental contamination during the sampling phases.

The fragments were found in dominant form in both polychaetes. After fibers, fragments are the most frequent type of microplastic in many invertebrates $\mathrm{s}^{20,23,30,47}$.

Our results show that the most of ingested microplastics in S. spallanzanii are transparent. Particles of this color are commonly found in organisms but are not predominant ${ }^{20,48,49}$. Instead, $H$. carunculata ingested pink microplastic particles in larger quantity, an unusual color in this type of studies. These particles could derive from the fragmentation of anthropogenic debris poured into the coastal environment but also from initially red particles that turn pink after chemical or environmental degradation.

In S. spallanzanii particles ranging in size from $330 \mu \mathrm{m}$ to $1 \mathrm{~mm}$ (class 2) were in greater concentration, whereas in $H$. carunculata particles ranging in size from 90 to $330 \mu \mathrm{m}$ (class 1 ) were found in large quantities. Microplastics can be confused for natural preys or ingested directly during feeding behavior due to their similar $\operatorname{size}^{50}$. Size selectivity has been observed in different species as oligochaetes ${ }^{51,52}$, decapod and euphausiid ${ }^{11}$.

Polymer identification is important as different polymers can have varying impacts on the marine ecosystem. Consistent with other studies ${ }^{20,23}$ our result show that most of ingested microplastics are made of polyethylene (PE), in both polychaetes. Although polyethylene is a low-density polymer, through the biofouling process and atmospheric agents, it sinks and becomes accessible to the benthic organisms ${ }^{53}$. This data could indicate the expansive use of plastic items made of polyethylene such as plastic bags, food packaging, trays and containers, various bottles, houseware. Polyethylene is the most produced plastic polymer ${ }^{54}$. Coastal areas are subjected to a high anthropogenic pressure, caused by the proximity of the urban areas, rivers, sewage and fishing activities, which makes them the most polluted areas by microplastics.

\section{Conclusion}

In the Mediterranean Sea there is a lack of widely accepted protocols to assess pollution by MPs in marine invertebrates. MPs are widespread in our seas and develop efficient protocols is important for monitoring and managing the impact of these marine litter on biodiversity.

Our study allowed to define an efficient digestion protocol for MPs extraction from two polychaetes species, S. spallanzanii and H. carunculata, in the Mediterranean Sea.

These two species of polychaetes were used for the first time to assess the impact of MP pollution. With this study the presence of MPs in S. spallanzanii and H. carunculata were verified and consequently their susceptibility to this type of pollution. Therefore, both polychaetes can be considered good bioindicators of the potential impact of MPs on biota and a useful tool for the monitoring of the coastal marine environments of the Mediterranean Sea.

Finally, the difference in MPs ingestion between species with different feeding strategies is very important and should be further investigated, possibly by conducting field studies and therefore considering all the interactions that occur naturally between organisms and the environment in which they are immersed.

\section{Methods}

Sampling and species. The species selection was made considering some ecological and practical aspects, including habitats, distribution, feeding strategy, species availability and sampling feasibility. Considering that the seafloors are areas with high accumulation of $\mathrm{MPs}^{9}$, we focused on benthic polychaetes since they are ubiquitous, they occupy practically all marine ecological niches, have different trophic strategies, and can be sampled easily.

To investigate MPs ingestion changes, depending on feeding strategy ${ }^{13}$, we selected two species with different feeding guilds: a suspension filter feeder, S. spallanzanii (Fig. 5a) and a predator, H. carunculata (Pallas, 1766) (Fig. 5b). Furthermore, both species were chosen based upon: their high density on coastal waters; wide distribution in Mediterranean Sea; the presence in various habitats; and affordable sampling effort; commonly found in environments known to have high densities of MPs.

The Mediterranean fanworm, S. spallanzanii, is a sessile benthic polychaete belonging to Sabellidae family ${ }^{55}$. S. spallanzanii live in a membranaceous tube attached to the hard substrates (rocks, artificial materials and benthic organisms) in the shallow subtidal zones, at a depth range of $1-30 \mathrm{~m}^{56}$. The species is a filter feeder that feeds on suspension particles as a dissolved organic matter in the water column and plankton ${ }^{57}$. Furthermore, this polychaete is able to filter large quantities of water, approximately $12 \mathrm{~m}^{3}$ per day ${ }^{58}$.

The bearded fireworm, $H$ carunculata, its vernacular name derives from the tufts of white, sharp, and venomous chaetae, is an errant benthic polychaete belonging to Amphinomidae family ${ }^{55}$. H. carunculata inhabits shallow water, including the intertidal zone and is common in a wide variety of natural and artificial habitats ${ }^{59}$. The bearded fireworm is a predator and a scavenger of sessile and slowly moving organisms, especially cnidarians, or injured prey and carrion, but it also feeds frequently on algae and detritus remains $\mathrm{s}^{60}$.

The choice of sampling sites was made considering two parameters: the feasibility of sampling the selected species in an appropriate number for their study and the selection of coastal areas in which it was assumed that the interaction between the selected species and the MPs dispersed in the marine environment was maximum. For this reason, were selected sites with high concentrations of MPs, that is harbours and coastal areas ${ }^{61,62}$.

In particular, S. spallanzanii has been sampled in harbours, where the species is particularly prevalent and grows on the vertical wall of the quay. H. carunculata, on the other hand, has been sampled along coastal areas, where the species is very frequent especially along the southern coasts of Italy.

Sampling was carried out from October 2018 to August 2019. A total of 108 specimens (52 S. spallanzanii and $55 \mathrm{H}$. carunculata) were collected. The sampling areas are located in three Italian regions of the Western Mediterranean Sea. 


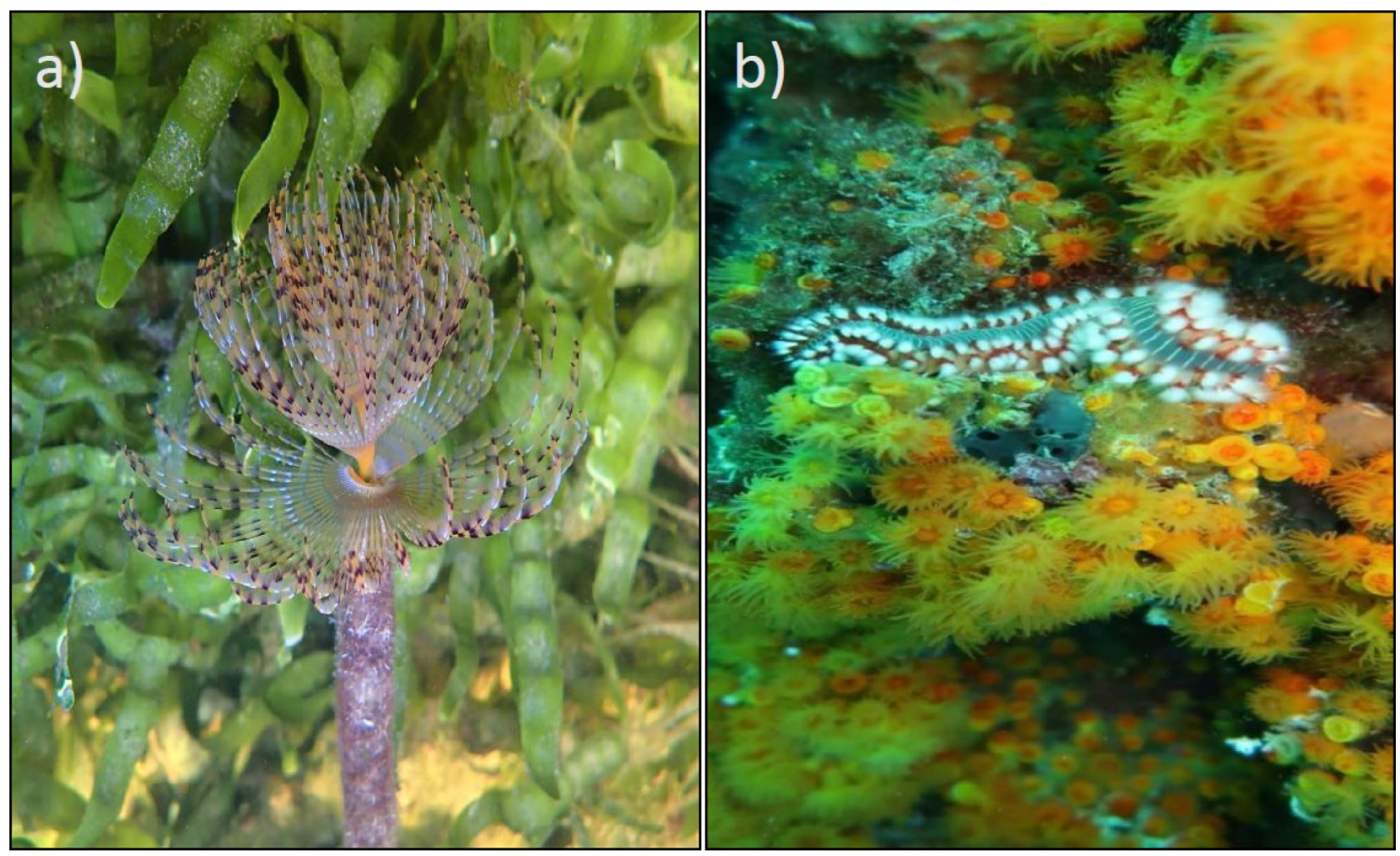

Figure 5. The investigated biological model: Sabella spallanzanii (A) and Hermodice carunculata (B). The photo images were taken by Paolo Tomassetti (a) and Fabrizio Fabroni (b).

S. spallanzanii samples were collected in three harbours, Ostia, Santa Marinella and Torre del Sale (Central and Northern Tyrrhenian Sea), (Fig. 6, sites Os, SM and Pi, respectively) located in Latium and Tuscany regions. The specimens were collected by hand along vertical wall of the quay.

H. carunculata samples were collected in two coastal areas, Secca del Mantineo and Scoglio della Galea (Southern Tyrrhenian Sea), (Fig. 6, sites Ma and Ga, respectively), in Calabria region. The specimens were collected by hand by scuba divers at depths between 10 and $20 \mathrm{~m}$.

The specimens of both species were rinsed with filtered sea water, placed in specific glass jars with $70 \%$ ethyl alcohol solution as fixative.

Different protocols comparison. S. spallanzanii samples were thawed at room temperature and extracted from the tubes.

The organisms were rinsed with filtered Milli-Q water, weight and length were recorded and each sample was collected in a jar to digestion treatment. We tested three different protocols:

Protocol 1) $10 \%$ potassium hydroxide $(\mathrm{KOH})$ solution to $3 \times$ the volume of the tissue, incubation at $60{ }^{\circ} \mathrm{C}$ for $12 \mathrm{~h}^{28}$

Protocol 2) $15 \mathrm{ml}$ of $15 \%$ hydrogen peroxide $\left(\mathrm{H}_{2} \mathrm{O}_{2}\right)$ for each gram of tissue, incubation at $50{ }^{\circ} \mathrm{C}$ for $12 \mathrm{~h}^{29}$.

Protocol 3) $10 \%$ potassium hydroxide $(\mathrm{KOH})$ solution to $3 \times$ the volume of the tissue, incubation at room temperature for 2-3 weeks ${ }^{27}$.

Digestion was performed on the whole body of organism. To evaluate the digestion efficiency, 10 samples for each protocol were used, resulting a total of 30 organisms.

Once the organic material was degraded, the jars content was filtered through glass microfiber membranes (Whatmann $\mathrm{GF} / \mathrm{F}^{\mathrm{m}}: 0.7 \mu \mathrm{m}$ pore size) using a vacuum pump system.

Before and after filtration, the membranes were dried at $40^{\circ} \mathrm{C}$ for $24 \mathrm{~h}$ and weighed on a scale (Mettler) with $0.01 \mathrm{mg}$ precision.

To evaluate digestion efficiency (\%) the following formula ${ }^{63}$ was used:

$$
\text { Digestion efficiency }(\%)=\frac{W i-(W a-W b)}{W i} \times 100
$$

where $\mathrm{Wi}=$ Initial weight of biological materials; $\mathrm{Wa}=$ Weight of dry membrane after filtration and $\mathrm{Wb}=\mathrm{Weight}$ of dry membrane before filtration.

Membrane clogging (filters g-1) was calculated using the following formula ${ }^{32}$ :

$$
\text { Membrane clogging }\left(\text { filters } \cdot g^{-1}\right)=\frac{N}{W i-(W a-W b)}
$$




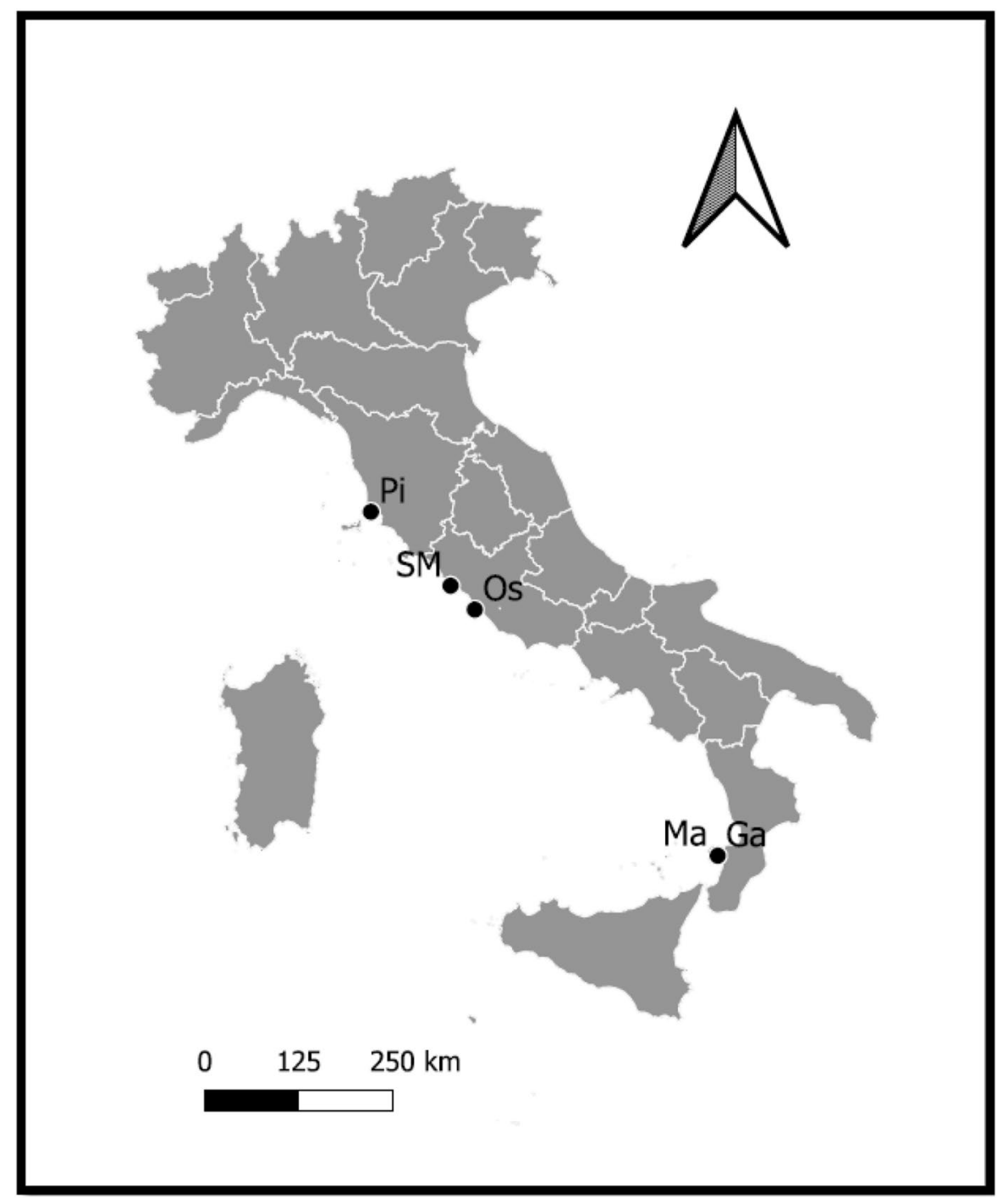

Figure 6. Location of the sampling sites of the Mediterranean fanworm Sabella spallanzanii (Os, SM, Pi) and the bearded fireworm Hermodice carunculata ( $\mathrm{Ga}$ and $\mathrm{Ma}$ ). In alphabetical order: $\mathrm{Ga}=\mathrm{Scoglio}$ della Galea; $\mathrm{Ma}=$ Secca del Mantineo; OS = Ostia; $\mathrm{Pi}=$ Piombino; $\mathrm{SM}=$ Santa Marinella. The figure is obtained by the QGIS software (ver. 3.16.7-Hannover, https://www.qgis.org/it/site/index.html).

where $\mathrm{N}=$ number of membranes required; $W i=$ Initial weight of biological materials; $W a=$ Weight of dry membrane after filtration and $W b=$ Weight of dry membrane before filtration.

Levene's Test of Equality of Variances was applicated to compare the digestion efficiencies of the three protocols. After the homogeneity test, the digestion efficiencies and the membrane clogging were compared performing nonparametric method, the Wilcoxon rank sum test.

Method adjustment. H. carunculata samples were rinsed with Milli-Q water to remove ethyl alcohol. Weight and length were recorded, and each sample was collected in a jar to digestion treatment.

$H$. carunculata samples were digested with the selected protocol for S. spallanzanii and later subjected to a further procedure due to the presence of many chaetes.

Since the chaetes of this species are calcareous an oxidizing agent was used. For each sample, the chaetes were taken and placed in a jar. A $5 \% \mathrm{HNO}_{3}+15 \% \mathrm{H}_{2} \mathrm{O}_{2}$ mixture ${ }^{32}$ to $3 \times$ the volume was added. The jars were incubated at $40^{\circ} \mathrm{C}$ for overnight and the solution obtained filtered through glass microfiber membranes (Whatmann GF/ $\mathrm{C}^{\mathrm{rw}}: 1.2 \mu \mathrm{m}$ pore size) using a vacuum pump system.

Microplastics in field collected samples. S. spallanzanii samples were digested with the selected procedure (protocol 3), H. carunculata samples were processed with the protocol developed in "method adjustment".

Ingested plastic items were quantified and subjected to physical and chemical characterization. 
Filters were visually analysed using a stereomicroscope (MARCA) and plastic particles were identified following the MEDSEALITTER protocol (MEDSEALITTER deliverable 4.6.1 "Final common monitoring protocol for marine litter"), considering the resistance to contact with tweezers, uneven edges, distinctive colours and those that show a dark sticky mark when touched with a hot needle ${ }^{64}$.

Shape type (fibre, fragment or film), colour (black, blue, green, red/pink, transparent or white) and size class (class 1: $90-330 \mu \mathrm{m}$, class 2: $330 \mu \mathrm{m}-1 \mathrm{~mm}$, class 3: 1-5 mm) ${ }^{3,10}$ were recorded for each identified plastic particles.

Fourier Transform Infrared spectrophotometer with Attenuated Total Reflection (ATR-FTIR, Thermo Fisher Scientific, Madison, WI, USA) was used to characterize polymers of items larger than $300 \mu \mathrm{m}$.

Contamination control. During all lab procedures a Tyvek protective suit was used and samples were processed under a laminar flow cabinet to avoid secondary contamination. Furthermore, all laboratory instruments and tools were washed with ultrapure water and checked under a stereomicroscope, to prevent crosscontamination. Procedural blanks were used in all steps (digestion, filtration and identification) for each batch of processed samples. No airborne or reagent contamination was recorded.

Statistical analysis. The difference in the frequency of occurrence and abundance of the ingested MPs between the two species, was analysed using Generalized Linear Models (GLM).

The null hypothesis is that the frequency of occurrence and abundance in the two species are equal, therefore MPs ingested amount in S. spallanzanii is the same in H. carunculata. The occurrence frequency data were analysed using binomial distribution. Instead, abundance was analysed using the negative binomial distribution, due to data overdispersion.

All statistical analysis were performed with the software R 3.5.3"65, using "lawstat"66, "mass"67 and "visreg"68 packages. The significance level was established to $5 \%$.

Received: 21 July 2021; Accepted: 20 September 2021

Published online: 22 October 2021

\section{References}

1. Geyer, R., Jambeck, J. R. \& Law, K. L. Production, use and fate of all plastics ever made. Sci. Adv. 3, e1700782 (2017).

2. Napper, I. E. \& Thompson, R. C. Marine plastic pollution: other than microplastic in Waste: A Handbook for Management, Second Edition (ed. Letcher, T. \& Vallero, D.) chapter 22, 425-442 (Academic Press, 2019).

3. Eriksen, M. et al. Plastic pollution in the world's oceans: more than 5 trillion plastic pieces weighing over 250,000 tons afloat at sea. PLOS ONE 9, e111913 (2014).

4. Sharma, S. \& Chatterjee, S. Microplastic pollution, a threat to marine ecosystem and human health: a short review. Environ. Sci. Pollut. Res. 24, 21530-21547 (2017).

5. Rocha-Santos, T. \& Duarte, A. C. A critical overview of the analytical approaches to the occurrence, the fate and the behavior or microplastics in the environment. TrAC Trends Anal. Chem. 65, 47-53 (2015).

6. Cózar, A. et al. Plastic accumulation in the mediterranean sea. PLoS ONE 10, e0121762 (2015).

7. Suaria, G. \& Aliani, S. Floating debris in the Mediterranean Sea. Mar. Pollut. Bull. 86, 494-504 (2014).

8. Auta, H. S., Emenike, C. U. \& Fauziah, S. H. Distribution and importance of microplastics in the marine environment: A review of the sources, fate, effects, and potential solutions. Environ. Int. 102, 165-176 (2017).

9. Woodall, L. C. et al. The deep sea is a major sink for microplastic debris. R. Soc. Open Sci. 1, 140317 (2014).

10. Kershaw, P., Turra, A. \& Galgani, F. Guidelines for the monitoring and assessment of plastic litter in the ocean. GESAMP Reports and Studies No. 99 (2019).

11. Desforges, J. P. W., Galbraith, M. \& Ross, P. S. Ingestion of microplastics by zooplankton in the Northeast Pacific Ocean. Arch. Environ. Contam. Toxicol. 69, 320-330 (2015).

12. Van Cauwenberghe, L., Claessens, M., Vandegehuchte, M. B. \& Janssen, C. R. Microplastics are taken up by mussels (Mytilus edulis) and lugworms (Arenicola marina) living in natural habitats. Environ. Pollut. 199, 10-17 (2015).

13. Setälä, O., Norkko, J. \& Lehtiniemi, M. Feeding type affects microplastic ingestion in a coastal invertebrate community. Mar. Pollut. Bull. 102, 95-101 (2016).

14. Amelineau, F. et al. Microplastic pollution in the Greenland Sea: Background levels and selective contamination of planktivorous diving seabirds. Environ. Pollut. 219, 1131-1139 (2016).

15. Zhu, J. et al. Cetaceans and microplastics: First report of microplastic ingestion by a coastal delphinid Sousa chinensis. Sci. Total Environ. 659, 649-654 (2019).

16. Sbrana, A. et al. Spatial variability and influence of biological parameters on microplastic ingestion by Boops boops (L.) along the Italian coasts (Western Mediterranean Sea). Environ. Pollut. 263, 114429 (2020).

17. De Sa, L. C., Luís, L. G. \& Guilhermino, L. Effects of microplastics on juveniles of the common goby (Pomatoschistus microps): confusion with prey, reduction of the predatory performance and efficiency, and possible influence of developmental conditions. Environ. Pollut. 196, 359-362 (2015).

18. Gallitelli, L., Cera, A., Cesarini, G., Pietrelli, L. \& Scalici, M. Preliminary indoor evidences of microplastic effects on freshwater benthic macroinvertebrates. Sci. Rep. 11, 720 (2021).

19. Karlsson, T. M. et al. Screening for microplastics in sediment, water, marine invertebrates and fish: Method development and microplastic accumulation. Mar. Pollut. Bull. 122, 403-408 (2017).

20. Bour, A., Avio, C. G., Gorbi, S., Regoli, F. \& Hylland, K. Presence of microplastics in benthic and epibenthic organisms: Influence of habitat, feeding mode and trophic level. Environ. Pollut. 243, 1217-1225 (2018).

21. Díaz-Castañeda, V., \& Reish, D. Polychaetes in environmental studies in Annelids as Model Systems in the Biological Sciences (ed. Shain, D. H.) chapter 11, 205-227 (Wiley, 2009).

22. Gusmão, F. et al. In situ ingestion of microfibres by meiofauna from sandy beaches. Environ. Pollut. 216, 584-590 (2016).

23. Missawi, O. et al. Abundance and distribution of small microplastics $(\leq 3 \mu \mathrm{m})$ in sediments and seaworms from the Southern Mediterranean coasts and characterisation of their potential harmful effects. Environ. Pollut. 263, 114634 (2020).

24. Piarulli, S. et al. Do different habits affect microplastics contents in organisms? A trait-based analysis on salt marsh species. Mar. Pollut. Bull. 153, 110983 (2020).

25. Knutsen, et al. Microplastic accumulation by tube-dwelling, suspension feeding polychaetes from the sediment surface: A case study from the Norwegian Continental Shelf. Mar. Environ. Res. 161, 105073 (2020). 
26. Lusher, A. L., Welden, N. A., Sobral, P. \& Cole, M. Sampling, isolating and identifying microplastics ingested by fish and invertebrates. Anal. Methods 9, 1346-1360 (2017).

27. Foekema, E. M. et al. Plastics in North Sea fish. Environ. Sci. Technol. 47, 8818-8824 (2013).

28. Rochman, C. M. et al. Anthropogenic debris in seafood: Plastic debris and fibers from textiles in fish and bivalves sold for human consumption. Sci. Rep. 5, 1-10 (2015).

29. Avio, C. G., Gorbi, S. \& Regoli, F. Experimental development of a new protocol for extraction and characterization of microplastics in fish tissues: First observations in commercial species from Adriatic Sea. Mar. Environ. Res. 111, 18-26 (2015).

30. Li, J., Yang, D., Li, L., Jabeen, K. \& Shi, H. Microplastics in commercial bivalves from China. Environ. Pollut. 207, 190-195 (2015).

31. Claessens, M., Van Cauwenberghe, L., Vandegehuchte, M. B. \& Janssen, C. R. New techniques for the detection of microplastics in sediments and field collected organisms. Mar. Pollut. Bull. 70, 227-233 (2013).

32. Bianchi, J. et al. Food preference determines the best suitable digestion protocol for analysing microplastic ingestion by fish. Mar. Pollut. Bull. 154, 1-9 (2020).

33. Cole, M. et al. Isolation of microplastics in biota-rich seawater samples and marine organisms. Sci. Rep. 4, 4528 (2014).

34. Dehaut, A. et al. Microplastics in seafood: Benchmark protocol for their extraction and characterization. Environ. Pollut. 215, 223-233 (2016).

35. Phuong, N. N., Poirier, L., Pham, Q. T., Lagarde, F. \& Zalouk-Vergnoux, A. Factors influencing the microplastic contamination of bivalves from the French Atlantic coast: Location, season and/or mode of life?. Mar. Pollut. Bull. 129, 664-674 (2018).

36. Valente, T. et al. Exploring microplastic ingestion by three deepwater elasmobranch species: a case study from the Tyrrhenian Sea. Environ. Pollut. 253, 342-350 (2019).

37. Thompson, R. C. et al. Lost at sea: Where is all the plastic?. Science 304, 838 (2004).

38. Mathalon, A. \& Hill, P. Microplastic fibers in the intertidal ecosystem surrounding Halifax Harbor Nova Scotia. Mar. Pollut. Bull. 81, 69-79 (2014).

39. Setälä, O., Fleming-Lehtinen, V. \& Lehtiniemi, M. Ingestion and transfer of microplastics in the planktonic food web. Environ. Pollut. 185, 77-83 (2014)

40. Jang, M., Shim, W. J., Han, G. M., Song, Y. K. \& Hong, S. H. Formation of microplastics by polychaetes (Marphysa sanguinea) inhabiting expanded polystyrene marine debris. Mar. Pollut. Bull. 131, 365-369 (2018).

41. Naidu, S. A., Rao, V. R. \& Ramu, K. Microplastics in the benthic invertebrates from the coastal waters of Kochi Southeastern Arabian Sea. Environ. Geochem. Health 40, 1377-1383 (2018).

42. Revel, M. et al. (2018). Accumulation and immunotoxicity of microplastics in the estuarine worm Hediste diversicolor in environmentally relevant conditions of exposure. Environ. Sci. Pollut. Res. 27, 3574-3583 (2018).

43. Näkki, P., Setälä, O. \& Lehtiniemi, M. Seafloor sediments as microplastic sinks in the northern Baltic Sea-Negligible upward transport of buried microplastics by bioturbation. Environ. Pollut. 249, 74-81 (2019).

44. Amin, R. M., Sohaimi, E. S., Anuar, S. T. \& Bachok, Z. Microplastic ingestion by zooplankton in Terengganu coastal waters, southern South China Sea. Mar. Pollut. Bull. 150, 110616 (2020).

45. Jang, M. et al. A close relationship between microplastic contamination and coastal area use pattern. Water Res. 171, 115400 (2020).

46. Torre, M., Digka, N., Anastasopoulou, A., Tsangaris, C. \& Mytilineou, C. Anthropogenic microfibres pollution in marine biota. A new and simple methodology to minimize airborne contamination. Mar. Pollut. Bull. 113, 55-61 (2016).

47. Courtene-Jones, W., Quinn, B., Murphy, F., Gary, S. F. \& Narayanaswamy, B. E. Optimisation of enzymatic digestion and validation of specimen preservation methods for the analysis of ingested microplastics. Anal. Methods 9, 1437-1445 (2017).

48. Digka, N., Tsangaris, C., Torre, M., Anastasopoulou, A. \& Zeri, C. Microplastics in mussels and fish from the Northern Ionian Sea. Mar. Pollut. Bull. 135, 30-40 (2018).

49. Ding, J. et al. Detection of microplastics in local marine organisms using a multi-technology system. Anal. Methods 11, 78-87 (2019).

50. Botterell, Z. L. et al. Bioavailability and effects of microplastics on marine zooplankton: A review. Environ. Pollut. 245, 98-110 (2019).

51. Huerta Lwanga, E. et al. Microplastics in the Terrestrial Ecosystem: Implications for Lumbricus terrestris (Oligochaeta, Lumbricidae). Environ. Sci. Technol. 50, 2685-2691 (2016).

52. Hurley, R. R., Woodward, J. C. \& Rothwell, J. J. Ingestion of microplastics by freshwater Tubifex worms. Environ. Sci. Technol. 51, 12844-12851 (2017)

53. Kowalski, N., Reichardt, A. M. \& Waniek, J. J. Sinking rates of microplastics and potential implications of their alteration by physical, biological, and chemical factors. Mar. Pollut. Bull. 109, 310-319 (2016).

54. PlasticsEurope. Plastics - the Facts 2019. An analysis of European plastics production, demand and waste data, p. 42 (2019). FINAL web version Plastics the facts2019 14102019.pdf.

55. Horton, T. et al. World Register of Marine Species (2021). https://doi.org/10.14284/170.

56. Currie, D. R., McArthur, M. A. \& Cohen, B. F. Reproduction and distribution of the invasive European fanworm Sabella spallanzanii (Polychaeta: Sabellidae) in Port Phillip Bay, Victoria Australia. Mar. Biol. 136, 645-656 (2000).

57. Giangrande, A. et al. Utilization of the filter feeder polychaete Sabella. Aquac. Int. 13, 129-136 (2005).

58. Stabili, L., Licciano, M., Giangrande, A., Fanelli, G. \& Cavallo, R. A. Sabella spallanzanii filter-feeding on bacterial community: ecological implications and applications. Mar. Environ. Res. 61, 74-92 (2006).

59. Schulze, A., Grimes, C. J. \& Rudek, T. E. Tough, armed and omnivorous: Hermodice carunculata (Annelida: Amphinomidae) is prepared for ecological challenges. J. Mar. Biolog. Assoc. U. K. 97, 1075-1080 (2017).

60. Jumars, P. A., Dorgan, K. M. \& Lindsay, S. M. Diet of worms emended: an update of polychaete feeding guilds. Annu. Rev. Mar. Sci. 7, 497-520 (2015).

61. Nel, H. A., Hean, J. W., Noundou, X. S. \& Froneman, P. W. Do microplastic loads reflect the population demographics along the southern African coastline?. Mar. Pollut. Bull. 115, 115-119 (2016)

62. Stolte, A., Forster, S., Gerdts, G. \& Schubert, H. Microplastic concentrations in beach sediments along the German Baltic coast. Mar. Pollut. Bull. 99, 216-229 (2015).

63. Karami, A. et al. A high-performance protocol for extraction of microplastics in fish. Sci. Total Environ. 578, 485-494 (2017).

64. Hermsen, E., Mintenig, S. M., Besseling, E. \& Koelmans, A. A. Quality criteria for the analysis of microplastic in biota samples: A critical review. Environ. Sci. Technol. 52, 10230-10240 (2018).

65. Developer Core Team, R. R: A language and environment for statistical computing. Vienna, Austria: R Foundation for Statistical Computing (2019).

66. Hui, W., Gel, Y. R. \& Gastwirth, J. L. Lawstat: An R package for law, public policy and biostatistics. J. Stat. Softw. 28, 1-26 (2008).

67. Ripley, B. et al. Support Functions and Datasets for Venables and Ripley's MASS (4th edition) (Springer, 2002).

68. Breheny, P. \& Burchett, W. Visualization of regression models using visreg. R. J. 9, 56-71 (2017).

\section{Author contributions}

S.V., J.B., M.S. and P.T. conceptualization; M.S. and P.T. supervisor; S.V. and J.B. writing; S.V. experimental part; J.B. methodology; F.F sampling. 


\section{Competing interests}

The authors declare no competing interests.

\section{Additional information}

Correspondence and requests for materials should be addressed to S.V. or M.S.

Reprints and permissions information is available at www.nature.com/reprints.

Publisher's note Springer Nature remains neutral with regard to jurisdictional claims in published maps and institutional affiliations.

(c) (1) Open Access This article is licensed under a Creative Commons Attribution 4.0 International License, which permits use, sharing, adaptation, distribution and reproduction in any medium or format, as long as you give appropriate credit to the original author(s) and the source, provide a link to the Creative Commons licence, and indicate if changes were made. The images or other third party material in this article are included in the article's Creative Commons licence, unless indicated otherwise in a credit line to the material. If material is not included in the article's Creative Commons licence and your intended use is not permitted by statutory regulation or exceeds the permitted use, you will need to obtain permission directly from the copyright holder. To view a copy of this licence, visit http://creativecommons.org/licenses/by/4.0/.

(C) The Author(s) 2021 